\title{
ASPECTOS DE UM MÉTODO PEDAGÓGICO PARA O LUNG'IE
}

\author{
Ana Lívia Agostinho ${ }^{1}$
}

\section{Resumo}

O objetivo deste artigo $^{2}$ é apresentar o método pedagógico do lung’Ie (AGOSTINHO, 2015; AGOSTINHO; ARAUJO, 2021a), língua crioula de base lexical portuguesa falada por menos de 200 pessoas na Ilha do Príncipe, São Tomé e Príncipe. A língua tem sido ensinada nas escolas do Príncipe da pré-escola até a $11^{\mathrm{a}}$ classe como disciplina optativa desde 2009, e como obrigatória desde 2016, mas há poucos materiais didáticos para seu ensino. Ademais, discutirei o papel da linguística formal aplicada ao ensino de línguas em situação minoritária na escola, tomando por base o caso do lung'Ie, que se configura como uma língua pouco descrita e em perigo de extinção.

Palavras-chave: Lung’Ie. Línguas crioulas. Línguas minoritárias. São Tomé e Príncipe. Ensino. Gramática.

\section{ASPECTS OF A PEDAGOGIC METHOD FOR LUNG'IE}

\begin{abstract}
The goal of this paper is to present the pedagogical method of Lung'Ie (AGOSTINHO, 2015; AGOSTINHO; ARAUJO, 2021a), a Portuguese-lexifier Creole language spoken by less than 200 people in Príncipe Island, São Tomé and Príncipe. The language has been taught in the schools of Príncipe from pre-school to the 11th grade as an optional subject since 2009, and as an obligatory subject since 2016, but there are few educational materials for its teaching. In addition, I will discuss the role of formal linguistics applied to language teaching in a minority situation at school, based on the case of Lung'Ie, which configures an underdescribed and endangered language.
\end{abstract}

Keywords: Lung'Ie. Creole languages. Minority languages. São Tomé and Príncipe. Teaching. Grammar.

\section{INTRODUÇÃO}

O lung'Ie (código ISO 639-3: pre) é uma língua crioula de base lexical portuguesa falada na República Democrática de São Tomé e Príncipe (STP). Também conhecido como principense ou crioulo da Ilha do Príncipe, o lung’ Ie, ou 'língua da Ilha', é também chamado lingw'Ie ou lungw'Ie pelos seus falantes. Este trabalho apesenta o método pedagógico do lung'Ie (AGOSTINHO, 2015; AGOSTINHO; ARAUJO, 2021a) e discute

\footnotetext{
${ }^{1}$ Universidade Federal de Santa Catarina (UFSC), Florianópolis - Santa Catarina, Brasil. Doutora em Filologia e Língua Portuguesa pela Universidade de São Paulo - USP. Professora do Departamento de Letras e Literaturas Vernáculas e do Programa de Pós-Graduação em Linguística da Universidade Federal de Santa Catarina. ORCID: http://orcid.org/0000-0002-2395-4961. E-mail: a.agostinho@ufsc.br.

${ }^{2}$ Este artigo é um desdobramento de Agostinho (2015) e Agostinho e Araujo (2021).
} 


\section{Linguagens - Revista de Letras, Artes e Comunicação - ISSN 1981- 9943 \\ Blumenau, v. 15, n. 1, p. 116-139, jan./abr. 2021. \\ DOI: http://dx.doi.org/10.7867/1981-9943.2021v15n1p116-139}

algumas questões em relação à sua inserção na escola. Como será mencionado adiante, o lung'Ie tem sido ensinado nas escolas do Príncipe da pré-escola até a $11^{\text {a }}$ classe $^{3}$ como disciplina optativa desde 2009, e como obrigatória desde 2016. Apesar disso, o método apresentado é o primeiro material didático para o ensino formal dessa língua nas escolas do Príncipe.

Antes da chegada dos portugueses, em 1470 ou 1471, as ilhas São Tomé e Príncipe, localizadas no Golfo da Guiné, eram desabitadas. A Ilha de São Tomé começou a ser povoada entre os anos 1480 e 1493 e a Ilha do Príncipe a partir de 1500. A ocupação de São Tomé e Príncipe passou por duas fases distintas: a primeira fase (séculos XV e XVI), com o impulso econômico do cultivo e produção da cana-de-açúcar, e a segunda fase se deu nos séculos XIX e XX, com o ciclo do cacau e do café. A primeira fase de povoamento de São Tomé no século XV foi marcada pela importação de uma massa populacional africana das mais diversas origens e línguas, principalmente de regiões como o delta do Níger, Congo e Angola. É neste cenário multilíngue que surge uma língua emergencial, do contato entre os colonos e os escravizados, que deu origem ao ProtoCrioulo do Golfo da Guiné (PGG) (cf. FERRAZ, 1979; HAGEMEIJER, 2011). Além do impulso no povoamento de São Tomé, houve a transplantação de escravizados, provavelmente falantes do PGG, para a Ilha do Príncipe, dando origem ao lung'Ie que seria, portanto, resultado das mudanças decorrentes de sua transplantação e isolamento, além das influências linguísticas e sociais sofridas a partir do contato com outros grupos.

A segunda fase de povoamento de STP, a partir do século XIX, trouxe trabalhadores contratados de outros países africanos, sobretudo de Cabo Verde, o que contribuiu ainda mais para o plurilinguismo dessa sociedade. Posteriormente, outros grupos de falantes de kabuverdianu foram levados ao Príncipe devido à escassez de mãode-obra local, relacionada a uma epidemia de doença do sono na ilha durante o início do século XX.

Atualmente, a população da Ilha do Príncipe é de cerca de 8 mil habitantes (INE, 2019). Menos de mil declaram usar o lung'Ie, de acordo com os dados do censo populacional de 2011 (INE, 2012). Contudo, o número de falantes nativos de lung'Ie, dependendo da fonte, varia de 20 (MAURER, 2009) a 200 (AGOSTINHO, 2015), com diferentes níveis de proficiência. Valkhoff (1966, p. 85) mencionou ter tido dificuldade para encontrar falantes nativos desta língua, já em 1958. Günther (1973, p. 50), por sua

\footnotetext{
${ }^{3}$ Equivalente ao Ensino Básico no Brasil.
} 


\section{Linguagens - Revista de Letras, Artes e Comunicação - ISSN 1981- 9943 \\ Blumenau, v. 15, n. 1, p. 116-139, jan./abr. 2021. \\ DOI: http://dx.doi.org/10.7867/1981-9943.2021v15n1p116-139}

vez, aponta que o lung'Ie estaria em processo de extinção, sendo substituído pelo santome e pelo português. Araujo e Agostinho (2010) apontam que a mídia e a escolarização (fenômenos pós-independência) dão ao português um prestígio que não pode ser rivalizado, o que implica um abandono crescente das línguas nacionais. Segundo Agostinho (2015), o kabuverdianu é falado por centenas de pessoas na Ilha do Príncipe, residentes, sobretudo, nas antigas roças coloniais ou em propriedades rurais isoladas. Há mais falantes nativos de kabuverdianu na Ilha do Príncipe do que falantes nativos de lung'Ie.

É certo, todavia, apontar que o lung’Je, como língua materna, possui uso muito restrito e está limitado à população da Ilha do Príncipe, mas há um aumento de interesse em relação à cultura principense ${ }^{4}$ e ao aprendizado do lung'Ie, embora não existam falantes monolíngues. Alguns jovens têm um conhecimento passivo da língua lung’Ie, mas não têm competência linguística para falar. É possível observar que a língua não é, portanto, transmitida intergeracionalmente. Um dos motivos apontados pelos próprios habitantes da Ilha do Príncipe é a relutância que os pais apresentavam em transmitir a língua, pois pensavam que o aprendizado do lung'Ie atrapalharia o aprendizado do português. Os locais contam que os pais e avós falavam em lung'Ie, mas as crianças sofriam abusos físicos e psicológicos se não respondessem em português. Além de fatores sociais, no início do século XX, houve uma epidemia de doença do sono que dizimou a população nativa do Príncipe, restando apenas 300 pessoas (GÜNTHER, 1973).

Segundo Agostinho et al. (2016), o lung'Ie, de acordo com a tipologia de Crystal (2000, p. 1-20), pode ser categorizado como uma língua ameaçada, devido à ausência de crianças a adquirindo como primeira língua, à atitude da comunidade que não tem buscado, majoritariamente, fazer uso regular do lung'Ie em todas as circunstâncias sociais, e, por fim, ao nível de impacto de outras línguas, principalmente o português, língua oficial e mais utilizada em todas as esferas sociais, e o kabuverdianu, já que há muitos falantes descendentes dos trabalhadores contratados que chegaram na Ilha no final do século XIX e começo do século XX.

\section{O LUNG'IE EM USO}

\footnotetext{
${ }^{4} \mathrm{O}$ nome do gentílico será principense, exceto se se referir a um cabo-verdiano nascido na Ilha do Príncipe. Sendo assim, principense é o nome do grupo étnico.
} 


\section{Linguagens - Revista de Letras, Artes e Comunicação - ISSN 1981- 9943 \\ Blumenau, v. 15, n. 1, p. 116-139, jan./abr. 2021. \\ DOI: http://dx.doi.org/10.7867/1981-9943.2021v15n1p116-139}

O estatuto político administrativo da Ilha do Príncipe foi aprovado pela Assembleia Nacional em 1994. A partir de então, a Ilha do Príncipe passou a ser uma Região Autônoma de São Tomé e Príncipe. Nos últimos anos, tem havido uma forte associação entre ser principense e conhecer o lung'Ie. Contudo, se o Governo Regional do Príncipe apoia essa ideia, o Governo Central se mostra menos entusiasmado em promover tal divisão identitária entre as duas ilhas. Desde 2009, a língua vem sendo ensinada nas escolas, resultado do incentivo à cultura principense pelo Governo Regional do Príncipe. De 2009 a 2014, o lung'Ie era ensinado desde a pré-escola (crianças de 3 a 5 anos) até a $11^{\text {a }}$ classe, sendo, contudo, uma disciplina optativa. A partir de 2016, as aulas a partir da $5^{\text {a }}$ classe passam a ser obrigatórias, tendo nota por presença e atividades. No entanto, não há professores treinados para lecionar a língua. Até recentemente, os professores de lung'Ie ensinavam somente listas de palavras e não havia aulas de estruturas linguísticas ou conversação. Apesar dos encontros quinzenais, cada professor define sozinho de que forma e com quais materiais ministrará suas aulas. Durante os últimos anos, porém, a discussão era muitas vezes pautada na ortografia, já que o lung’Ie ainda não tinha uma ortografia padrão até 2010, e a discussão sobre a escolha entre uma escrita fonética ou etimológica ainda não havia sido resolvida ${ }^{5}$.

A falta de instrumentos linguísticos é, portanto, uma grande dificuldade para o aprendizado do lung'Ie nas escolas, já que estes instrumentos permitem notadamente uma maior estabilidade na metodologia de ensino (AUROUX, 1998). Em relação ao material para ensino do lung'Ie nas escolas, há o método pedagógico de Agostinho (2015), que foi revisado, atualizado e publicado com o título Lung'Ie, lunge no: método para aprender lung'Ie (AGOSTINHO; ARAUJO, 2021), e o material didático Vika xina lung'Ie de Lavres e Lavres (2016), publicado em São Tomé com tiragem de 200 cópias, que consiste em um glossário com palavras e sentenças e uma lista de formas verbais. Os autores do livro Vika xina lung'Ie são de STP, sendo o primeiro autor falante nativo de lung'Ie. Atualmente os professores de lung'Ie têm acesso a parte do material impresso ${ }^{6}$ de

\footnotetext{
${ }^{5}$ Com a implementação do Alfabeto Unificado para a Escrita das Línguas Nativas de São Tomé e Príncipe (ALUSTP) (PONTÍFICE et al., 2010), todos os instrumentos linguísticos passarão a utilizar a mesma grafia padronizada. No entanto, apesar de sua implementação, o acordo ortográfico continua desconhecido pela maioria dos principenses, inclusive para os professores de lung'Ie. Pela minha experiência, os professores só passaram a ter contato efetivo com o ALUSTP em 2016.

${ }^{6}$ Nos últimos trabalhos de campo que realizei, em 2016 e 2019, levei cópias de parte do método impresso para os professores para realização de workshops.
} 


\section{Linguagens - Revista de Letras, Artes e Comunicação - ISSN 1981- 9943 \\ Blumenau, v. 15, n. 1, p. 116-139, jan./abr. 2021. \\ DOI: http://dx.doi.org/10.7867/1981-9943.2021v15n1p116-139}

Agostinho (2015), arquivo digital ${ }^{7}$ de Agostinho (2015) e Agostinho e Araujo (2021), e a Lavres e Lavres (2016).

Cerca de duas vezes por semana são transmitidos programas de rádio em lung’'Ie, na Rádio Regional do Príncipe. Os programas consistem em conversas informais sobre a língua, sobre a vida no Príncipe, sobre política, apresentações musicais, lições sobre a língua, traduções para o lung'Ie, entre outros. Os ouvintes podem telefonar para a produção do programa radiofônico e tirar dúvidas sobre a língua durante as transmissões. Além disso, há transmissões de músicas em lung’Ie, mas a maioria da programação musical é em português, kabuverdianu e santome. Além das aulas na escola e programas de rádio, há um encontro semanal chamado palixa na lung'Ie 'conversar em lung'Ie', onde se elege um tema sobre o qual os presentes deverão discorrer em lung'Ie. O encontro também é, muitas vezes, transmitido pela Rádio Regional do Príncipe.

Segundo Agostinho et al. (2016, p. 611),

atividades de difusão do lung'Ie e sobre a cultura do Príncipe na comunidade ajudariam a manter a língua em uso pelos mais velhos e a incentivar seu aprendizado pelos mais novos. É essencial que o falante possa ter um motivo para aprender uma língua minoritária, seja ele participar de forma mais ativa na comunidade, se comunicar com os mais velhos, preservar sua identidade, poder participar de certas atividades, entre outros.

Para Orlandi (2009), a língua é parte da identidade pessoal do falante além de ser patrimônio histórico da humanidade, uma vez que a perda de uma língua equivale à perda da cultura. No mesmo sentido, Fishman (2006) coloca que as línguas minoritárias deveriam ser consideradas como recursos naturais de uma nação e que são imprescindíveis para seu enriquecimento linguístico e cultural. Segundo Agostinho et al. (2016), estas preocupações existem entre os professores de lung'Ie e na camada jovem da população do Príncipe, apesar de os jovens não falarem a língua. Os autores observam que a língua é reconhecida pelos alunos como uma forma de se diferenciar das línguas de São Tomé e de outros países, e como afirmação de sua identidade.

Dessa forma, é possível dizer que o planejamento e a padronização da língua, por meio de instrumentos linguísticos, preencherá uma lacuna no ensino do lung’'Ie, abrindo caminho para novas publicações e materiais didáticos, bem como colaborando com o crescente interesse pela língua e para a sua promoção como língua nacional de São Tomé e Príncipe.

\footnotetext{
7 Vale ressaltar que, apesar de o arquivo digital ter sido disponibilizado aos professores e ao Governo Regional e estar disponível online, a maioria dos professores não tem acesso a computadores e internet.
} 


\section{Linguagens - Revista de Letras, Artes e Comunicação - ISSN 1981- 9943 \\ Blumenau, v. 15, n. 1, p. 116-139, jan./abr. 2021. \\ DOI: http://dx.doi.org/10.7867/1981-9943.2021v15n1p116-139}

\section{O MÉTODO PEDAGÓGICO: LINGUÍSTICA NA ESCOLA}

O livro Lung'Ie, lunge no: método para aprender lung'Ie (AGOSTINHO; ARAUJO, 2021a) ${ }^{8}$, doravante Método, é um material produzido por linguistas para o ensino do lung'Ie nas escolas do Príncipe. Tem como língua-veículo o português, língua oficial de São Tomé e Príncipe, empregada na escolarização básica e fundamental e língua materna da maior parte da população. As gramáticas prévias do lung’Ie (GÜNTHER, 1973; MAURER, 2009) não servem como instrumentos para uso pedagógico propriamente dito, pois são descrições voltadas ao público científico e não foram formatadas como material didático. Além disso, a primeira tem o alemão como línguaveículo e a segunda, o inglês. Assim, pela primeira vez, temos um material linguístico acessível aos habitantes da Ilha do Príncipe.

Apesar de ser voltado ao ensino escolar de uma língua minoritária, o Método é resultado de anos de trabalho de campo na Ilha do Príncipe e de descrição e análise de dados linguísticos através de métodos e teorias formais (cf. AGOSTINHO, 2016, por exemplo). Nesse sentido, é possível refletir sobre a conciliação do trabalho de descrição e análises formais e da elaboração de instrumentos linguísticos para línguas em situação minoritária.

Por ter um viés científico, o Método não traz julgamentos de valor sobre as formas linguísticas aqui apresentadas. Embora seja um trabalho acadêmico, as notas gramaticais foram feitas de forma simplificada para auxiliar o entendimento de alunos e professores nas escolas do Príncipe. Ao mesmo tempo, esperamos que a descrição linguística do Método seja apenas uma base para que os professores possam a partir dele criar novas situações didáticas, e que o material com textos e exercícios auxiliem a melhor forma de conduzir sua aula. Portanto, o público-alvo deste trabalho é formado por professores e usuários do lung'Ie, que careciam de material didático, mas também é acessível a interessados em aprender a língua em geral. O público acadêmico também poderá se beneficiar desse Método, cuja estrutura foi livremente inspirada no método Parlons Capverdien - langue et culture, de Quint (2003). O sistema de tempo-modoaspecto utilizado nas notas gramaticais foi baseado na descrição de Maurer (2009), embora haja modificações relevantes e vários aspectos possuem uma nova interpretação

\footnotetext{
${ }^{8} \mathrm{O}$ livro pode ser baixado no link: https://agostinho.paginas.ufsc.br/lungie/.
} 


\section{Linguagens - Revista de Letras, Artes e Comunicação - ISSN 1981- 9943 \\ Blumenau, v. 15, n. 1, p. 116-139, jan./abr. 2021. \\ DOI: http://dx.doi.org/10.7867/1981-9943.2021v15n1p116-139}

para os fenômenos gramaticais do lung'Ie. Para uma versão do método com glosa linguística, ver Agostinho (2015).

O Método se encaixa em uma tentativa de revitalização linguística através da educação (cf. HORNBERGER; DE KORNE, 2018) e se faz necessário pelo interesse da comunidade na manutenção e revitalização do lung'Ie, que funciona como símbolo de sua identidade (AGOSTINHO et al., 2016). Nesse sentido, o papel do linguista de campo é importante nessa empreitada e trabalhos com este objetivo podem auxiliar em uma possível revitalização linguística (cf. WARNER et al., 2007).

Apesar do Método ainda não ter sido publicado em meio físico, os professores de lung'Ie tem cópias impressas e digitais e estão utilizando diferentes versões do material desde 2016. Em 2016 e 2019 foram realizados dois workshops sobre a utilização do Método com os professores de lung'Ie no Príncipe. Estes workshops puderam auxiliar na preparação da versão final do Método e contar com a participação e aceitação dos professores e da comunidade local.

\subsection{ESTRUTURA}

O Método contém dezessete lições com textos em lung'Ie (seguidos de equivalentes em português), que remetem à cultura e tradição locais. O conteúdo deste método pedagógico está dividido em quatro partes: lições, apêndices, índices e glossário. O Método contém inicialmente uma apresentação do sistema ortográfico, seguido por dezessete lições com textos e diálogos, além de notas gramaticais sobre a morfossintaxe do lung'Ie. Em cada lição, há também vocabulário, tópicos gramaticais, texto sobre cultura (também em lung'Ie e português), vocabulário da seção de cultura, exercícios focando os tópicos gramaticais de cada lição e vocabulário temático complementar. Além dos exercícios de fixação, há exercícios comunicativos e de interpretação e produção de textos escritos e orais. Ao final do Método, há um apêndice com textos de apoio para o professor, com os quadros de pronomes e verbos e, por fim, as respostas dos exercícios. Apresentamos ao final do Método um glossário lung'Ie/português e português/lung'Ie, com cerca de 1.750 entradas, contendo todas as palavras utilizadas nas lições e um índice gramatical remissivo, com os tópicos gramaticais expostos nas lições. Assim, temos a seguinte estrutura: 


\section{Linguagens - Revista de Letras, Artes e Comunicação - ISSN 1981- 9943 \\ Blumenau, v. 15, n. 1, p. 116-139, jan./abr. 2021. \\ DOI: http://dx.doi.org/10.7867/1981-9943.2021v15n1p116-139}

Vocabulário do texto

Notas gramaticais

Vocabulário temático

Exercícios

Texto de cultura

Vocabulário do texto de cultura

Traduções

Textos de apoio ao professor

Quadros de pronomes e verbos

Chave de correção dos exercícios

\section{3. Índices}

Notas gramaticais

Tópicos de cultura

Vocabulários temáticos

\section{Glossários}

\section{Apêndices}

O material foi elaborado utilizando-se o Alfabeto Unificado para as Línguas Nativas de São Tomé e Príncipe (ALUSTP), publicado no Diário da República de São Tomé e Príncipe no dia 14 de agosto de 2013 através do Decreto n 19/2013. O tom fonológico ${ }^{10}$ não é marcado na grafia do ALUSTP. As versões em português dos diálogos e das traduções das notas gramaticais podem diferir da norma escolar padrão.

\subsection{OS DADOS DO MÉTODO}

O corpus e as análises presentes no Método são fruto do trabalho de campo realizado na Ilha do Príncipe durantes os anos 2010, 2011, 2013, 2014, 2016 e 2019.

Os textos de cada lição foram produzidos de modo a exemplificar algumas formas gramaticais. Os textos de cultura são compostos de traduções livres do português para o lung'Ie feitas por falante nativo, ou de textos espontâneos de um falante nativo traduzido para o português, com o auxílio do mesmo. Sentenças que não fazem parte dos diálogos foram somadas ao corpus, para constituírem exemplos nas notas gramaticais. No vocabulário de cada lição, constam as palavras que aparecerem pela primeira vez. $\mathrm{O}$ vocabulário dos textos de cultura funciona da mesma forma, porém, uma palavra que já apareceu em um vocabulário de lição anterior não se repete. Os diálogos e textos em lung'Ie foram gravados com falantes nativos in loco durante o trabalho de campo e estão disponibilizados como material audiovisual do Método. ${ }^{11}$ Os falantes auxiliaram na elaboração dos textos sobre cultura e puderam revisar os diálogos e as traduções.

\footnotetext{
${ }^{9}$ Para uma análise mais aprofundada dessa proposta e das ortografias anteriores, cf. Agostinho e Araujo, 2010.

${ }^{10}$ Para uma análise do sistema tonal do lung’Ie, ver Agostinho e Hyman, 2021.

${ }^{11} \mathrm{O}$ material audiovisual pode ser acesso no link: https://agostinho.paginas.ufsc.br/lungie/.
} 
O corpus do dicionário lung'Ie/português, português/lung'Ie (AGOSTINHO; ARAUJO, em preparação), com cerca de 5.000 palavras, incluindo compostos, variantes e topônimos, foi utilizado no vocabulário temático de cada lição. No final do método, há um glossário com todas as palavras dos textos (lições e cultura) e vocabulários temáticos, com a referência àquela lição em que aparecem primeiro. Utilizamos também os corpora de Günther (1973), com cerca de 800 entradas, e de Maurer (2009), com cerca de 1.650 entradas, nas notas gramaticais. Sempre que um dado for de outro autor, a fonte é citada em nota de rodapé.

\section{EXEMPLO - LIÇÃO 2: N WE FYA}

Esta seção traz a lição 2 da forma que é apresentada no Método. À medida que as lições avançam, são apresentadas estruturas mais complexas e textos mais longos. Vale ressaltar que a versão que será utilizada nas escolas do Príncipe é a sem glosa linguística e é esta reproduzida abaixo. As traduções aparecerão no final da lição. 
Linguagens - Revista de Letras, Artes e Comunicação - ISSN 1981- 9943

Blumenau, v. 15, n. 1, p. 116-139, jan./abr. 2021.

DOI: http://dx.doi.org/10.7867/1981-9943.2021v15n1p116-139

\subsection{DIÁlOGO}

Figura 1. Diálogo da Lição 2
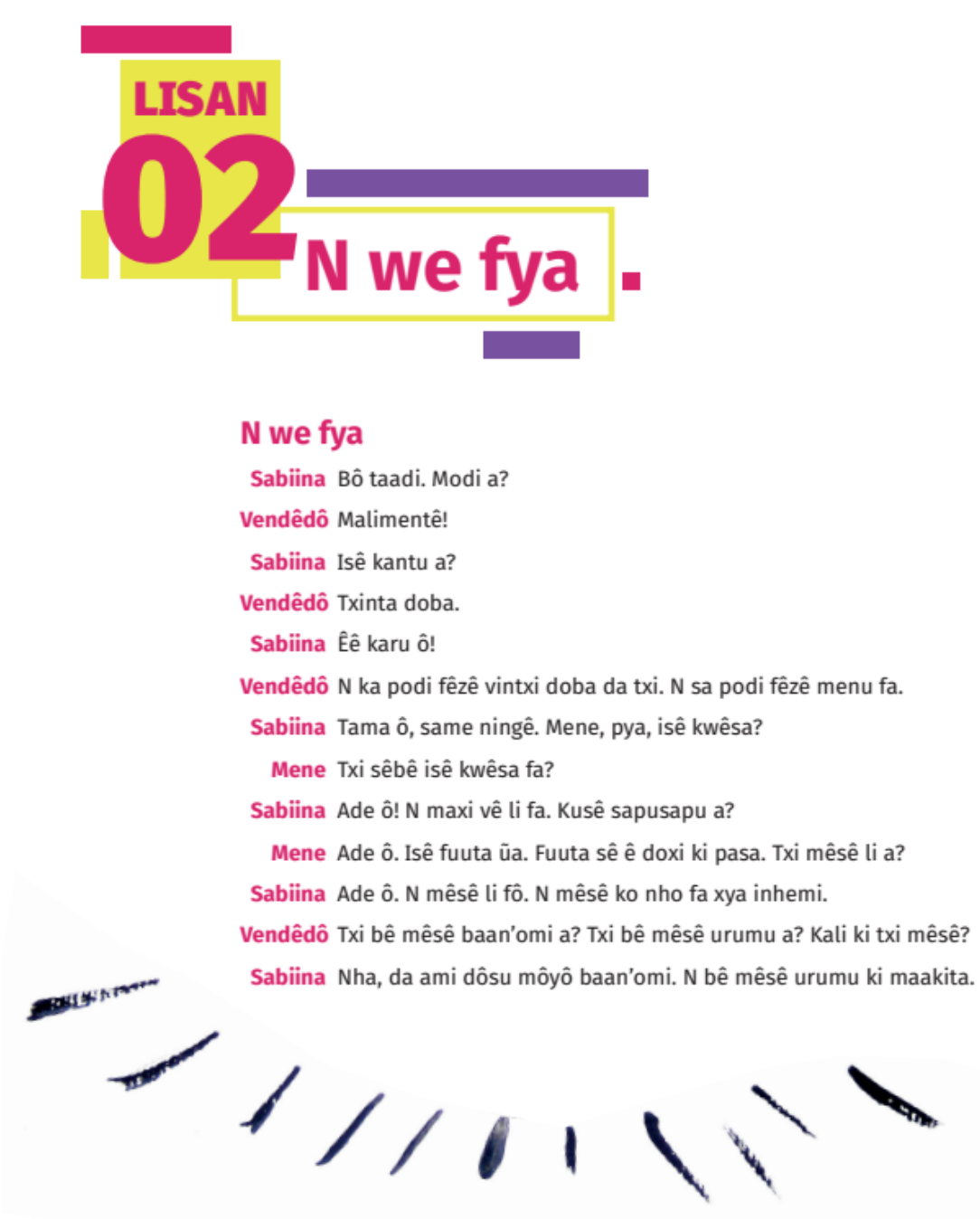

Fonte: Agostinho e Araujo (2021a, p. 14) 
Linguagens - Revista de Letras, Artes e Comunicação - ISSN 1981- 9943

Blumenau, v. 15, n. 1, p. 116-139, jan./abr. 2021.

DOI: http://dx.doi.org/10.7867/1981-9943.2021v15n1p116-139

Figura 2. Vocabulário da Lição 2

\section{VOCABULÁRIO}

baan'omi, baana-omi

1. N. banana-da-terra;

2. N. banana-pão

bô ADV. bom

doba N. dobra. Moeda

de STP

dôsu NUM. dois

doxi ADJ. doce

êê INTERJ. nossa!

fa PART. partícula de

negação

fa ô PART. cf. fa

fêzê v. fazer

fô PART. cf. fa

fuuta $N$. fruta-pão

inhemi N. inhame

kali, kwali PRO. qual kantu PRO. quanto

karu ADJ. caro

ki 1. CONJ. com; 2. CONJ. e

(entre nomes); 3. PRO. que

ko nho ADV. nada

kusê 1. PRO. isso; 2. PRO.

isto

kwêsa PRO. o quê

li PRO. 3SG.OD

maakita N. malagueta

maxi fa 1. ADV. nunca; 2

ADV. ainda não

menu ADV. menos

mêsê 1. v. amar; 2. v.

gostar; 3 . v. querer

mili NUM. mil

môyô N. penca de banana

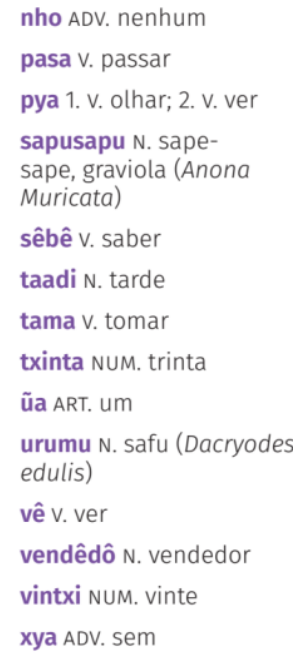

Fonte: Agostinho e Araujo (2021a, p. 15)

\subsection{NOTAS GRAMATICAIS}

Nesta lição, abordaremos novamente os pronomes pessoais, além do não-passado, da frase negativa, dos pronomes interrogativos, dos demonstrativos e dos artigos. Apresentaremos também a ausência da marca de plural e a conjunção ki.

\section{Pronomes Pessoais II}

Na lição 1, vimos os pronomes de primeira e de segunda pessoa e suas várias formas. Nesta lição, veremos os pronomes de terceira pessoa do singular. Na posição de sujeito temos ê e na posição de objeto direto temos li. As outras posições serão vistas adiante.

\section{(1) $\hat{\mathbf{E}}$ vê txi.}

'Ele viu você.'

(2) Txi vê li.

'Você viu ele.'

(3) Sabiina vê li.

'Sabrina viu ele.'

(4) $\hat{\mathbf{E}}$ vê Sabiina.

'Ele viu a Sabrina.' 


\section{Linguagens - Revista de Letras, Artes e Comunicação - ISSN 1981- 9943 \\ Blumenau, v. 15, n. 1, p. 116-139, jan./abr. 2021. \\ DOI: http://dx.doi.org/10.7867/1981-9943.2021v15n1p116-139}

Os pronomes pessoais que aparecem pela primeira vez em cada lição estão em negrito, para diferenciá-los dos vistos nas lições anteriores. Nesta lição, aparecem o pronome sujeito e objeto da terceira pessoa do singular.

Figura 3. Pronomes pessoais

\begin{tabular}{|c|c|c|c|c|c|}
\hline & \multicolumn{3}{|c|}{ Argumento } & \multirow{2}{*}{$\begin{array}{l}\text { Não argumento } \\
\text { Adjunto do nome } \\
\text { - possessivos }\end{array}$} & \multirow{2}{*}{ Deslocados } \\
\hline & Sujeito & $\begin{array}{l}\text { Objeto } \\
\text { direto }\end{array}$ & $\begin{array}{c}\text { Objeto } \\
\text { indireto }\end{array}$ & & \\
\hline $1 S G$ & $n$ & & ami & me & ami \\
\hline $2 S G$ & txi & txi & atxi & tê & atxi \\
\hline $3 S G$ & $\hat{\mathbf{e}}$ & li/e & & & \\
\hline
\end{tabular}

Fonte: Agostinho e Araujo (2021a, p. 16)

\section{Verbos estativos}

Em lung'Ie, verbos estativos ${ }^{12}$ e verbos que denotam ação ou atividade se comportam de maneira diferente. Os verbos estativos são aqueles que denotam um estado ou experiência, como sêbê 'saber', mêsê ‘querer' e podi 'poder'. Nesta lição, estudaremos os verbos estativos. Verbos que chamaremos aqui 'de ação' são aqueles que denotam uma ação ou atividade controlada ou não controlada, como da 'dar', zuda 'ajudar' e fala 'falar'. Os verbos de ação serão introduzidos nas lições 3 e 4.

Os verbos estativos podem ser divididos em duas classes: zero-estativo e ka-estativo:

a) TIPO ZERO-ESTATIVO:

Nesta lição, aparecem os verbos de zero-estativo sêbê ‘saber' e mêsê 'querer'. Nessa classe, o imperfectivo não é marcado.

(5) Txi sêbê isê kwêsa fa a?

'Você não sabe o que é isto?'

(6) Txi mêsê li a?

'Você o quer?'

\footnotetext{
${ }^{12}$ Incluímos no conjunto de verbos estativos os verbos do tipo experienciais e benefactivos de estado.
} 


\section{Linguagens - Revista de Letras, Artes e Comunicação - ISSN 1981- 9943 \\ Blumenau, v. 15, n. 1, p. 116-139, jan./abr. 2021. \\ DOI: http://dx.doi.org/10.7867/1981-9943.2021v15n1p116-139}

\section{b) TIPO KA-ESTATIVO: PODI/PO}

Nesta lição, o verbo de ka-estativo que vimos é: podi 'poder.' Nessa outra classe de verbos estativos, o marcador aspectual ka (que tem outras funções além dessa, explicadas nas próximas lições) marca o não-passado. Em sentenças simples, o ka vem imediatamente depois do sujeito e antecede o verbo.

\section{(7) N ka po fêzê vintxi doba da atxi.}

'Eu posso fazer por vinte dobras para você'

Figura 4. Ka-estativo

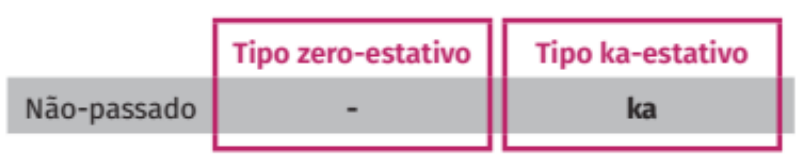

Fonte: Agostinho e Araujo (2021a, p. 17)

Não há diferença de significado entre os verbos de zero-estativo e de ka-estativo (Maurer, 2009, p. 72), portanto não tem como saber se um verbo estativo pertence a uma ou outra classe. Sendo assim, é preciso aprender a classe de cada verbo.

Figura 5. Verbos zero-estativos e ka-estativos

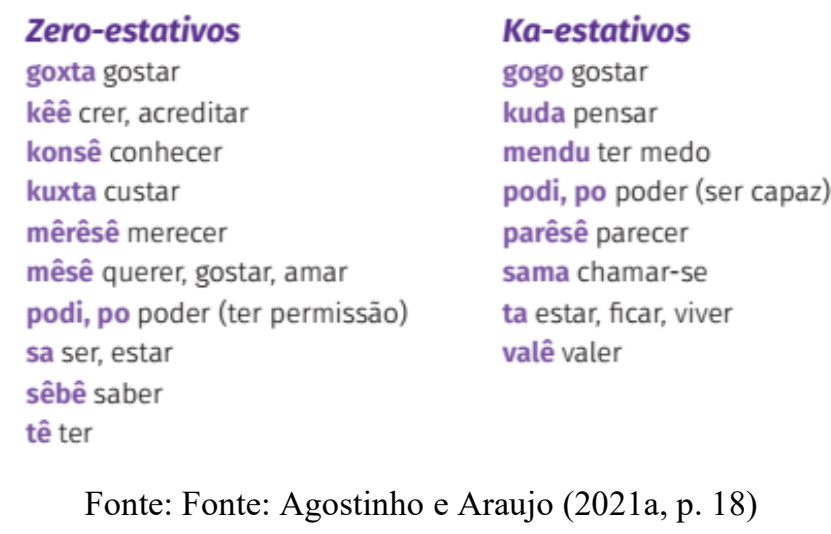

III. Negação

A negação em lung'Ie é feita, normalmente, com a inserção da partícula negativa fa no final da sentença, como em:

\section{(8) $\quad$ mêsê li fa.}

'Eu não o quero.' 


\section{Linguagens - Revista de Letras, Artes e Comunicação - ISSN 1981- 9943 \\ Blumenau, v. 15, n. 1, p. 116-139, jan./abr. 2021. \\ DOI: http://dx.doi.org/10.7867/1981-9943.2021v15n1p116-139}

As partículas enfática $\hat{\mathbf{o}}(\mathbf{f a}+\hat{\mathbf{o}}$ é sempre alterado para fô) e interrogativa a aparecem depois de fa, como em:

\section{(9) N mêsê urumu fô!}

Eu não quero safu, não!

(10) Txi mêsê urumu fa a?

'Você não quer safu?'

IV. Pronomes interrogativos ${ }^{13}$

Há oito tipos de pronomes interrogativos em lung'Ie, a saber:

Figura 6. Pronomes interrogativos

\begin{tabular}{|r|c|c|}
\cline { 2 - 3 } Tipo & Pronome interrogativo & Glosa \\
\hline Pessoa & ningê & 'quem' \\
\hline Coisa & ki, kwa, kwêsa & 'que', 'que coisa', 'o quê' \\
\hline Propriedade & kali/kwali & 'qual' \\
\hline Lugar & kumi/kumin & 'onde' \\
\hline Tempo & kantora, kidya, kiora & $\begin{array}{c}\text { 'quando', 'que horas', } \\
\text { 'que dia', 'que horas' }\end{array}$ \\
\hline Maneira & modi & 'como' \\
\hline Quantidade & kantu & 'quanto' \\
\hline Motivo & $\begin{array}{c}\text { pidi kwê manda, } \\
\text { pidi kwêsa, pidi }\end{array}$ & 'por que' \\
\cline { 2 - 3 } & &
\end{tabular}

Fonte: Agostinho e Araujo (2021a,p. 18)

Nesta lição, veremos 4 desses tipos: de coisas, de propriedade, de maneira e de quantidade.

a) kwêsa-O QUÊ

Este elemento pode ocorrer no início ou no fim da sentença.

\section{(11) Isê kwêsa?}

'O que é isso?'

\section{(12) Kwêsa txi mêsê?}

'O que você quer?'

\footnotetext{
${ }^{13}$ A partícula interrogativa a pode ser omitida. Ver lição 1.
} 
b) $\quad$ kali - QUAL

O sintagma nominal com kali pode aparecer no início ou no final da sentença.

\section{(13) Kali txi mêsê?}

'Qual você quer?'

(14) Txi mêsê kali?

'Você quer qual?'

(15) Kali inhemi txi mêsê?

'Qual inhame você quer?'

(16) Txi mêsê kali inhemi?

'Você quer qual inhame?'

c) modi - $\mathrm{COMO}$

A palavra modi aparece na lição 1 e novamente na lição 2 . O modi pode aparecer no início ou no final da sentença.

(17) Modi a?

'Como (vai)?'

(18) Modi nomi tê a?

'Seu nome é qual?'

(19) Nomi tê modi?

'Qual é seu nome?'

d) kantu - QUANTO

O sintagma nominal com kantu pode aparecer no início ou no final da sentença.

(20) Isê kantu a?

'Quanto é isso?'

(21) Kantu isê a?

'Quanto é isso?' 


\section{(22) Urumu kantu a?}

'Quanto é o safu?'

(23) Kantu doba txi tê a?

'Quantas dobras você tem?'

(24) Txi tê kantu doba a?

'Você tem quantas dobras?'

V. Demonstrativos

Há três tipos de pronomes demonstrativos em lung’Ie, que aparecem nesta lição.

a) isê - 'ISTO, ISSO'

Comporta-se como um nome, pois não precisa de outra parte para formar um sintagma.

\section{(25) Isê kantu a?}

'Quanto é isso?'

(26) Isê kwêsa?

'O que é isso?'

b) sề - 'ESTE, ESSE'

Comporta-se como pronome adjetivo, pois necessita qualificar um nome para formar um sintagma.

(27) Urumu sê kantu a?

'Quanto é esse safu?'

\section{(28) Sapusapu sê karu ô!}

'Esta graviola está cara!'

c) kwisê/kusê - 'ESTA COISA, ISTO, ESSA COISA, ISSO'

Comporta-se como nome, pois não precisa de outra parte para formar um sintagma. É formado por kwa 'coisa' + isê 'isto, isso'. 
(29) Kusê sapusapu a?

'Esta coisa é uma graviola?'

(30) Txi mêsê kusê a?

'Você quer esta coisa?'

\section{Artigo}

O lung'Ie não possui artigos definidos e indefinidos propriamente ditos. Como veremos mais adiante, todos os outros numerais ocorrem antes do nome. No entanto, o numeral ũa 'um' pode ser usado como um artigo e pode indefinir um sujeito. $\mathrm{O}$ ũa sempre ocorre depois do nome, seja qual for a sua função.

\section{(31) Isê fuuta ũa.}

'Isso é uma fruta-pão.'

\section{(32) Ningê ũa vê li.}

'Alguém viu ele.'

VII. Ausência de marca de plural

O lung'Ie não tem marca morfológica de plural. Normalmente, o contexto é suficiente para resolver a ambiguidade entre o singular e o plural. Assim, quando dizemos N mêsê baan'omi no contexto do diálogo acima, ou seja, comprando frutas e legumes em um mercado, queremos dizer ‘eu quero bananas', pois não compraríamos apenas uma banana.

Outra estratégia é colocar ine antes do nome que será pluralizado, como em ine afika 'os africanos' e ine minu 'as crianças'. Neste caso, o ine funciona como um artigo definido plural. Além dessa, podemos ter a reduplicação como estratégia de plural, como em minu kwa-kwa 'coisinhas'. Nas lições seguintes, veremos estas construções com mais detalhes.

\section{Conjunção - ki}

O ki aparece no diálogo desta lição com a função da conjunção aditiva 'e'. É usado somente entre nomes. Vale lembrar que a conjunção aditiva oracional é i, e aparece nas notas gramaticais da lição 1.

\section{(33) N mêsê urumu ki maakita.}

'Eu quero safu e malagueta.' 
Linguagens - Revista de Letras, Artes e Comunicação - ISSN 1981- 9943

Blumenau, v. 15, n. 1, p. 116-139, jan./abr. 2021.

DOI: http://dx.doi.org/10.7867/1981-9943.2021v15n1p116-139

(34) N kume urumu ki sapusapu ki fuuta.

'Eu comi safu, graviola e fruta-pão.'

O ki tem outras funções além dessa, que serão vistas adiante.

4.3 VOCABULÁRIO TEMÁTICO - MERC 


\section{Linguagens - Revista de Letras, Artes e Comunicação - ISSN 1981- 9943 \\ Blumenau, v. 15, n. 1, p. 116-139, jan./abr. 2021. \\ DOI: http://dx.doi.org/10.7867/1981-9943.2021v15n1p116-139}

Figura 7. Vocabulário temático da Lição 2

\section{VOCABULÁRIO TEMÁTICO}

\section{Mercado}

akara N. banana frita cortada

em lâminas

mampata $\mathrm{N}$. residuo de óleo de

akê N. pote de barro

palma

baana $\mathrm{N}$. banana

mantega $\mathrm{N}$. manteiga

baana-gamixeli $\mathrm{N}$. banana-

-gromichel

masan $\mathrm{N}$. maçă

mixikitu 1. N. cf. ufya-mixikitu;

2. N. mosquito

baana-kongô N. banana-do-

-congo

mondyoko N. mandioca

mutambu N. armadilha

baana-masan N. banana-maçã

baana-mye $\mathrm{N}$. banana-pão

pequenina

mutendê $\mathrm{N}$. broto de palmeira

mutete $N$. cesto feito com folha

de palmeira

nanaji 1. N. abacaxi; 2. N. ananás

N. banana-prata

fenza-vêêdê $N$. vagem

fyan-mondyoko N. farinha de mandioca

pipinu N. pepino

tujyan $\mathrm{N}$. tesoura

txiigu 1. N. farinha de trigo;

2. N. trigo

tximatxi $\mathrm{N}$. tomate

udumu N. pilão

ufya-mixikitu N. folha-

mosquito. Tipo de tempero tradicional

ukpami $\mathrm{N}$. secador de peixe

ukyebu, ukyabu N. quiabo

umpan 1. N. pão; 2. N. fruta-pão

usuda $\mathrm{N}$. pimenta

usuda-malaka N. pimenta bolinha

kuxta v. custar

kwaa N. corda

kwentu N. coentro

utaji N. utaji. Tipo de tempero tradicional

laanza N. laranja

likatxi N. alicate

makêkê N. jiló

maman N. mamão

Fonte: Agostinho e Araujo (2021a, p. 22)

\subsection{EXERCÍCIOS}

I. Verta as seguintes frases para o lung'Ie e depois coloque na forma negativa.

a. Você quer safus.

b. Eu, eu quero inhames.

c. Sabrina mora em Santo Antônio.

d. Os inhames estão caros.

e. A banana-pão é gostosa demais.

II. Verta para o lung'Ie. 

a. Você sabe o que é isso? - Eu sei!
b. Quanto custam os inhames?
c. Você sabe quanto é?
d. Você não quer safus? - Sim, eu quero!
e. Você quer dois cachos de banana-pão? - Não, eu não quero!

III. Complete com modi, kantu ou kali e depois traduza.
a. Maakita
a? Txinta doba.
b. N pya urumu, n pya baan'omi. $\mathrm{N}$ sêbê ki n mêsê fa.
c. Maakita sê karu! I sapusapu sê a?
d. Mene a? Malimentê!
e. txi mêsê? N mêsê isê!

IV. Complete com isê, sê ou kusê e depois traduza.

a. fuuta a? Ade ô. sapusapu.

b. tixi mêsê a?

c. Fuuta karu!

d. Txi pya ? kantu a?

e. Ningê seradô.

f. $\quad \mathrm{N}$ mêsê sapusapu

V. Kwa ki txi sa kuxtumadu sa kopa na fya a? Pidi pôfêsô di zuda txi.

VI. Konvesa na lung'Ie ki migu tê kwali kwa di kume txi goxta. Xikêvê palava sê ki txi xina.

\subsection{KUTWA}




\section{Linguagens - Revista de Letras, Artes e Comunicação - ISSN 1981- 9943 \\ Blumenau, v. 15, n. 1, p. 116-139, jan./abr. 2021. \\ DOI: http://dx.doi.org/10.7867/1981-9943.2021v15n1p116-139}

Figura 8. Cultura da Lição 2

\section{Fya*}

Na fya Ie sa bii dya tudu pe na sumana. Ningê tudu pe ka podi kopa pêxi feexku xya pa we fya pemya sedu. Txyan di pêxi a vya sa vendê kwa ôtô modi otalisa, fuuta, tempa Ie, izêtxi-pwema ki pilha kwa vya. Lala bê tê fya di vendê upanu, kwa pô xikola, kwa pô kuxan i ki pilha kwa ôtô vya.

Txyan di fya, a ka vê ningê mutu sa vendê pêxi, umpan, bôlô, paxte ki pilha kwa ôtô di kume na uga posan. Na modi ki a ka vê na Santome, fya Ie ê kitxi, a sa vê pilha kwa sa vendê modi na Santome fa. Maji wo sê, kêtê kêtê a sa vê kwa mutu sa vendê modi na Santome. Maji ê vya tê kwa mutu ki sa pixiza di vendê na fya fa, mo fala makêkê, binzela, fuuta, maxkan, kola ki pilha kwa, pidi vijin ka da ôtô vijin, migu bê ka da migu.

\section{Compreensão do texto}

1 o que se pode encontrar no mercado do Príncipe?

De que outra maneira é possível adquirir comida sem ir ao mercado?

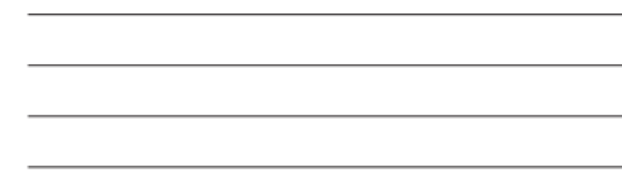

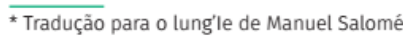

\section{VOCABULÁRIO}

bii 1. v. abrir

2. v. começar

binzela $\mathrm{N}$. berinjela

bôlô $\mathrm{N}$. bolo

fya 1. N. mercado;

2. N. feira

kitxi $A D J$. pequeno

kola N. cola

kopa v. comprar

kume v. comer

kuxan N. cozinha

maxkan $\mathrm{N}$.

manjericão

migu $\mathrm{N}$. amigo

otalisa N. hortaliças

paxte N. pastel

pemya ADV. pela

manhã

pêxi N. peixe

pixiza v. precisar

sedu $N$. cedo

tempa N. tempero

upanu 1. N. pano;

2. N. roupa

vendê v. vender

vijin $\mathrm{N}$. vizinho

wo sê ADV. agora

xya ADV. somente

Fonte: Agostinho e Araujo (2021a, p. 26)

\subsection{TRADUÇÕES}

\section{EU FUI AO MERCADO}

S- Boa tarde. Como vai?

$\mathrm{V}$ - Mais ou menos!

S- Me diz o preço desses inhames.

$\mathrm{V}$ - Trinta dobras.

S- Nossa, que caro!

$\mathrm{V}$ - Se você quiser, eu posso fazer por vinte dobras para você.

S- Toma, senhora. Manuel, olha, o que é isto?

M- Você não sabe o que é isto?

S- Não! Eu nunca vi. Isto é graviola?

M- Não. Isso é uma fruta-pão. Essa fruta-pão é boa demais. Você quer?

S- Não. Eu não quero. Eu não quero comprar nada além de inhames.

V- Você também quer banana-pão? Você também quer safu? Qual você quer?

S- Sim, me dê duas pencas de banana-pão. Eu também quero um pouco de safu e malagueta. 


\section{Linguagens - Revista de Letras, Artes e Comunicação - ISSN 1981- 9943 \\ Blumenau, v. 15, n. 1, p. 116-139, jan./abr. 2021. \\ DOI: http://dx.doi.org/10.7867/1981-9943.2021v15n1p116-139}

\section{CULTURA: MERCADO}

O mercado do Príncipe abre todos os dias da semana. Para comprar peixe fresco, é preciso ir ao mercado bem cedo. Além de peixe, são vendidos legumes, frutas, temperos tradicionais, azeite de palma, etc. Há também roupas, materiais escolares, utensílios para cozinha e uma infinidade de outros produtos.

Além do mercado, há sempre pessoas vendendo peixes, pães e bolos pelas ruas da cidade. Em comparação a São Tomé, o mercado do Príncipe é pequeno e não tem tanta variedade. Mas há muitos produtos que não é preciso vender no mercado, como jiló, berinjela, fruta-pão, manjericão, noz de cola, entre outros, pois é mais fácil negociar uma troca com vizinhos e amigos.

\section{CONSIDERAÇÕES FINAIS}

Este trabalho apresentou o método pedagógico do lung'Ie (AGOSTINHO, 2015; AGOSTINHO; ARAUJO, 2021a), língua crioula de base lexical portuguesa falada na Ilha do Príncipe em São Tomé e Príncipe. O lung'Ie é falado por menos de 200 pessoas com mais de 60 anos e está em perigo de extinção, não sendo mais aprendido pelos jovens há algumas gerações.

O Método foi produzido para preencher uma lacuna em relação à inexistência de material didático para o ensino da língua nas escolas, que ocorre desde 2009, como tentativa de manutenção e revitalização linguística. A falta de material didático de línguas em perigo de extinção contribui para o silenciamento de seus falantes e os estudos em linguística formal pode ter um papel importante em relação à produção de instrumentos linguísticos para línguas em situação minoritária.

Apesar de apresentar metodologia e embasamento teórico diferentes de outros tipos de produção científica, projetos como o aqui apresentado podem auxiliar no planejamento linguístico em línguas em processo de extinção e disseminar o conhecimento científico sobre essas línguas para os membros de suas comunidades. Outro exemplo é a proposta de utilização de jogos de linguagem no aprendizado de lung'Ie, uma ferramenta pedagógica que pode auxiliar no processo de documentação e revitalização juntamente com outros materiais, mas que também é produtiva para apreender e perceber estruturas silábicas da língua, do ponto de vista do aluno e do linguista (AGOSTINHO; ARAUJO, 2021b). Nesse sentido, acreditamos que o linguista que trabalha com línguas pouco descritas, minorizadas e em perigo de extinção, caso seja de interesse da comunidade em questão, deva se envolver na produção deste tipo de material direcionado aos falantes, com ativa participação da comunidade em questão.

\section{REFERÊNCIAS}


AGOSTINHO, A. L. Fonologia e método pedagógico do lung’Ie. Tese de Doutorado, Universidade de São Paulo, 2015.

AGOSTINHO, A. L. Fonologia do lung'Ie. München: Lincom. 2016.

AGOSTINHO, A. L.; LIMA, M. B.; ARAUJO, G. A. O Lung'Ie na educação escolar de São Tomé, São Tomé e Príncipe. Trabalhos em Linguística Aplicada, v. 55, n. 3, p. 591-618, 2016.

AGOSTINHO, A. L.; ARAUJO, G. A. De. Lung'Ie, lunge no: método para aprender lung'Ie. São Paulo: FFLCH/USP, 2021a.

AgOSTINHO, A. L.; ARAUJO, G. A. De. Playing with language: Three language games in the Gulf of Guinea. Language Documentation \& Conservation, Honolulu, v. 15, p. 219-238, 2021b.

AGOStinhO, A. L.; ARAUJO, G. A. De. Dicionário lung’Ie-português. Em preparação.

AGOSTINHO, A. L.; HYMAN, L. M. Word Prosody in Lung'Ie: One System or Two? Probus, v. 33, n. 1, p. 57-93, 2021.

ARAUJO, G. A.; AGOSTINHO, A. L. Padronização das línguas nacionais de São Tomé e Príncipe. Língua e Instrumentos Linguísticos, 26, p. 49-81, 2010.

ARAUJO, G. A; HAGEMEIJER, T. Dicionário livre do santome-português. São Paulo: Hedra. 2013.

AUROUX, S. Língua e hiperlíngua. Língua e instrumentos linguísticos, Campinas, v. 1, p. 17$30,1998$.

CRYSTAL, D. Language Death. Cambridge: CUP, 2000.

FERRAZ, L. I. The creole of São Tomé. Johannesburg: Witwatersrand University Press, 1979.

FISHMAN, J. A. Language Maintenance, Language Shift, and Reversing Language Shift, In: BHATIA, T. K.; RITCHIE, W. C. (Ed.). The Handbook of Bilingualism. Oxford: Blackwell. 2006, p. 406-436.

GÜNTHER, W. Das portugiesische Kreolisch der Ilha do Príncipe. Marburg an der Lahn: Im Selbstverlag. 1973.

HAGEMEIJER, T. The Gulf of Guinea Creoles: Genetic and Typological Relations. Journal of Pidgin and Creole Languages, v. 26, n. 1, p. 111-154. 2011.

HORNBERGER, N. H.; DE KORNE, H. Is revitalization through education possible? In: HINTON, L.; HUSS, L.; ROCHE, G. (Ed.). The Routledge Handbook of Language Revitalization. [S. 1.]: Routledge, 2018, p. 94-104. 
INSTITUTO NACIONAL DE ESTATÍSTICA. INE: São Tomé e Príncipe em números 2011. 2012. Disponível em: http://www.ine.st/docs/2012/Censos/2012/index.html. Acesso em: 07 ago. 2013.

INSTITUTO NACIONAL DE ESTATÍSTICA. INE: São Tomé e Príncipe em números 2017. 2019.

LAVRES, N. F. da M. da C.; LAVRES, M. da G. de O. Vika xina lung'Ie. São Tomé: Lexonics, 2016.

MAURER, P. Lung’Ie. Londres: Battlebridge Publications: 2009.

ORLANDI, E. P. Processos de descolonização linguística: as representações da língua nacional. In: GALVES, C.; GARMES, H.; RIBEIRO, F. R. (Orgs.). África-Brasil: caminhos da língua portuguesa. Campinas: Editora UNICAMP. 2009, p. 211-223.

PONTÍFICE, J.; ALCÂNTARA, C.; AFONSO, B. C.; HAGEMEIJER, T.; MAURER, P. 2010. Alfabeto Unificado para a Escrita das Línguas Nativas de S. Tomé e Príncipe (ALUSTP).

Manuscrito.

QUINT, N. Parlons Capverdien - langue et culture. Paris/Budapest/Torino: L'Harmattan: 2003.

VALKHOFF, M. F. Studies in Portuguese and Creole. Johannesburg: Witwatersrand University Press: 1966.

WARNER, N.; LUNA, Q.; BUTLER, L. Ethics and Revitalization of Dormant Languages: The Mutsun Language. Language Documentation \& Conservation, v. 1, n. 1, p. 58-76, 2007.

\section{AGRADECIMENTOS}

A autora agradece à CAPES, à FAPESP (processo 2011/06107-6) e ao Programa de PósGraduação em Linguística da Universidade Federal de Santa Catarina. 